\title{
Endophytic Penicillium funiculosum LHL06 secretes gibberellin that reprograms Glycine max L. growth during copper stress
}

Abdul Latif Khan ${ }^{1,2,3}$ and In-Jung Lee ${ }^{1 *}$

\begin{abstract}
Background: Heavy metal pollution in crop fields is one of the major issues in sustainable agriculture production. To improve crop growth and reduce the toxic effects of metals is an ideal strategy. Understanding the resilience of gibberellins producing endophytic fungi associated with crop plants in metal contaminated agriculture fields could be an important step towards reducing agrochemical pollutions. In present study, it was aimed to screen and identify metal resistant endophyte and elucidate its role in rescuing crop plant growth and metabolism during metal stress.
\end{abstract}

Results: Fungal endophyte, Penicillium funiculosum LHL06, was identified to possess higher growth rate in copper (Cu) and cadmium contaminated mediums as compared to other endophytes (Metarhizium anisopliae, Promicromonospora sp. and Exophiala sp.). P. funiculosum had high biosorption potential toward copper as compared to cadmium. An endophyte-metal-plant interaction was assessed by inoculating the host Glycine max L. plants with P. funiculosum during Cu (100 $\mathrm{MM})$ stress. The Cu application adversely affected the biomass, chlorophyll and total protein content of non-inoculated control plants. The control plants unable to synthesis high carbon, hydrogen and nitrogen because the roots had lower access to phosphorous, potassium, sulphur and calcium during Cu treatment. Conversely, $P$. funiculosum-association significantly increased the plant biomass, root physiology and nutrients uptake to support higher carbon, hydrogen and nitrogen assimilation in shoot. The metal-removal potential of endophyte-inoculated plants was significantly higher than control as the endophyte-association mediated the Cu uptake via roots into shoots. The symbiosis rescued the host-plant growth by minimizing Cu-induced electrolytic leakage and lipid peroxidation while increasing reduces glutathione activities to avoid oxidative stress. P. funiculosum-association synthesized higher quantities of proline and glutamate as compared to control. Stress-responsive abscisic acid was significantly downregulated in the plant-metal-microbe association.

Conclusion: The endophyte $P$. funiculosum symbiosis counteracted the Cu stress and reprogrammed soybean plant growth. Such growth promoting and stress mediating endophytes can be applied at field levels to help in bioremediation of the polluted agricultural fields.

Keywords: Glycine max L, Root essential nutrients, Endophytism, Copper stress

\section{Background}

Heavy metal pollution has become a major issue in the agriculture fields due to recent advancements in industrial and urban activities. Metals like cadmium (Cd) and copper $(\mathrm{Cu})$ are added in the agriculture soil through contaminated irrigated water. Higher concentrations of

\footnotetext{
* Correspondence: ijlee@knu.ac.kr

${ }^{1}$ Department of Biological Sciences \& Chemistry, University of Nizwa, Nizwa 616, Sultanate of Oman

Full list of author information is available at the end of the article
}

these metal cause toxicity to living cells, even at very low concentrations. Cadmium can inhibit the growth and yield of plants as a result of chlorosis, instability of lipid membrane, oxidative damage [1] and reaction with functional biochemicals [2-6]. Copper $(\mathrm{Cu})$ is naturally distributed in soil whilst plays essential role in plant growth. It is also important in its function to synthesize enzymes and proteins which are used in various metabolic processes by plants [7]. However, higher concentration is

\section{() Biomed Central}


toxic for crops as it interferes with numerous physiological processes [7].

Lack of immobility and solubility of these toxic metals further synergized the negative effects on plant growth. Phytoremediation is argued as a promising method to rehabilitate the polluted soil. However, most of the metal-accumulating plants are not suitable due to their small biomass and slow growth rates. Therefore, it is deemed important to further develop remediation strategies for heavy metal contaminated soils [3,8-10]. In this regard, interactions among metals, microbes and plants have attracted much attention because of the biotechnological potential of microorganisms to remove metals directly from polluted media and the possible role of microorganisms in promoting plant growth in metal contaminated soils [10]. Among microbes, endophytic fungi have been recently known to produce plant growth regulators (like gibberellins and auxins) and extend plant tolerance under abiotic and biotic stresses [11-17]. In addition, it has been shown that endophytic fungi such as Chaetomium globosum [18], Neotyphodium coenophialum [19] and Neotyphodium endophytes [20] have the potential to remove soil contaminants by enhancing phytoremediation potential of the host-plants [21-25].

Soybean growth is often hindered by the calamities of extreme environmental conditions, thus reducing crop yield and growth. Soybean is known to play essential role in human health and food intake specially the East-Asian countries [24]. Previously, we isolated and identified endophytic fungi from the roots-tissues of soybean plants (Table 1). These endophytic fungal species produced gibberellins, increased plant growth and enhanced tolerance against salinity and drought stresses. Endophytes Penicillium funiculosum, Metarhizium anisopliae, and Exophiala sp. extended greater benefits to host-plants by ameliorating host-physiology during stress conditions. The endophytes were bioactive in promoting Waito-C (gibberellins biosynthesis mutant) and Dongjin-beyo (normal gibberellins pathway) rice cultivars. P. funiculosum and Exophiala $s p$ were detected to produce physiologically active gibberellins through advanced GC/MS selected ion monitor (SIM) techniques [14-16]. Promicromonospora sp. was observed to produce Ascotoxin [17] and inhibited the seed germination of lettuce and weed seed. Metarhizium anisopliae was inactive to produce gibberellins but played active role to help the host-plants to resist salinity stress [15]. Since these endophytes were active to counteract abiotic stresses and produced phytohormones/secondary metabolites, therefore, we hypothesized that due to this potential they might help the host-plants to avoid heavy metal toxicity. To elucidate plant-microbe-metal interactions, we initially screened four endophytic fungal strains to know their potential to bioaccumulate $\mathrm{Cu} / \mathrm{Cd}$ in contaminated mediums. The bioactive strain was then associated with host soybean plants to assess the metal removal capacity and influence on the essential biochemicals and plant growth.

\section{Results}

Screening for metal resistant endophyte

Four different endophytic fungi ( $P$. funiculosum, $M$. anisopliae, Promicromonospora sp. and Exophiala sp Table 1) isolated from soybean plants were screened for their potential to bio-accumulate metal. The results showed that Promicromonospora $s p$. and Exophiala sp. did not grow well during ten-days of incubation in $\mathrm{Cu}$ and $\mathrm{Cd}$ polluted mediums. Conversely, the growth of P. funiculosum and $M$. anisopliae was significantly higher during $\mathrm{Cu}$ as compared to $\mathrm{Cd}$ (Figure 1). The growth area of Promicromonospora sp., Exophiala sp., M. anisopliae and $P$. funiculosum was $0.4 \pm 0.01,0.5 \pm 0.02,3.2 \pm 0.07$ and $5.3 \pm 0.09 \mathrm{~cm}^{2}$ during $\mathrm{Cu}$ stress respectively. In case of $\mathrm{Cd}$ stress, the growth of all endophytes was not significantly different from each other. Though the growth area of $M$. anisopliae and $P$. funiculosum was a little higher but it was not significant.

Upon high growth of $M$. anisopliae and P. funiculosum in $\mathrm{Cu} / \mathrm{Cd}$ stress, we carefully removed the mycelial pads and subjected it to ICP-MS analysis to determine the level of metal accumulation. P. funiculosum contained significantly higher concentration of $\mathrm{Cu}$ as compared to M. anisopliae while $\mathrm{Cd}$ accumulation was not significantly different between each other (Figure 1). The phosphate and sulphate contents were significantly higher in $P$. funiculosum as compared to $M$. anisopliae. Thus, on the basis of growth dynamics and higher accumulation rate of copper, P. funiculosum was selected for further experiments of plant-metal-microbe interactions.

\section{$P$. funiculosum-association influenced soybean growth and photosynthesis pigments during $\mathrm{Cu}$ stress}

The bioactive $P$. funiculosum was associated with host soybean plants to assess the effect of symbiosis on the plant growth during $\mathrm{Cu}$ stress. Endophyte association $(\mathrm{E}+)$ with host soybean plants significantly increased the shoot length and biomass as compared to non-inoculated control (E-) plants (Table 2). During Cu stress, the shoot length, shoot and root fresh biomass were considerably reduced in the endophyte-free $(\mathrm{E}-\mathrm{Cu})$ plants as compared to $P$. funiculosum infection. The reduced growth of shoot and root was quite visible and significant in E- plants than E + with or without $\mathrm{Cu}$ stress (Figure 2). Reduced leaf area and increased leaf curling was significantly higher in $\mathrm{E}$ - than $\mathrm{E}+$ plants under $\mathrm{Cu}$ stress. This enhanced growth was also confirmed from the quantities of essential elements i.e. carbon, hydrogen and nitrogen. The elemental analyses showed that carbon content was significantly higher in the shoot parts of $\mathrm{E}+$ plants as compared to E- with or without 
Table 1 Strains of the fungal endophytes used to determine growth rate under high copper conditions

\begin{tabular}{|c|c|c|c|c|c|}
\hline Name & Plant hormones production & Stress condition & Identification & GeneBank ID & References \\
\hline \multirow[t]{2}{*}{ Penicillium funiculosum LHLO6 } & $\mathrm{GA}_{1}, \mathrm{GA}_{4}, \mathrm{GA}_{8}, \mathrm{GA}_{9}$ & Salinity (70 and $140 \mathrm{mM}$ ) & ITS rDNA & HM017065 & Khan et al. [15] \\
\hline & & & LSU rDNA & & \\
\hline \multirow[t]{2}{*}{ Metarhizium anisopliae LHL07 } & ND & Salinity (70 and $140 \mathrm{mM}$ ) & ITS rDNA & HM017066 & Khan et al. [16] \\
\hline & & & LSU rDNA & & \\
\hline \multirow[t]{2}{*}{ Exophiala sp LHL08 } & $\mathrm{GA}_{1}, \mathrm{GA}_{3}, \mathrm{~A}_{4}, \mathrm{GA}_{7}, \mathrm{GA}_{5}, \mathrm{GA}_{8}, \mathrm{GA}_{9}, \mathrm{GA}_{12}, \mathrm{GA}_{20}$ & Salinity and drought & ITS rDNA & HM623425 & Khan et al. [14] \\
\hline & & & LSU rDNA & & \\
\hline Promicromonospora sp. LK1 & ND & NST & ITS rDNA & JQ288104 & Khan et al. [17] \\
\hline
\end{tabular}

GA (gibberellins); ITS (internal transcribed spacer); LSU (large subunit); ND (not detected); NST (no-stress treatments).

the excursion of $\mathrm{Cu}$ stress (Figure 2). This suggests higher plant biomass assimilation during the symbiosis of endophyte. The hydrogen content was similar in $\mathrm{E}+$ and E- plants under normal growth conditions however under $\mathrm{Cu}$ stress, it was significantly higher in $\mathrm{E}+$ plants than E-. It suggests that the relative proportion of water was significantly higher in the shoot of endophyte-inoculated plants than non-inoculated control plants (Figure 2). Nitrogen assimilation in shoot part of the plants plays a pivotal role in maintaining improved growth and metabolism. During plant-endophyte-metal interaction, the endophyte-inoculated $\mathrm{E}+$ plants had assimilated significantly higher level of nitrogen in shoot as compared to control E- plants during $\mathrm{Cu}$ stress (Figure 2).

To further assess the role of endophyte in improving plant physiology and relieving the adverse effects of $\mathrm{Cu}$ stress, photosynthetic pigments like chlorophyll and total carotenoid were determined. The results in Figure 3

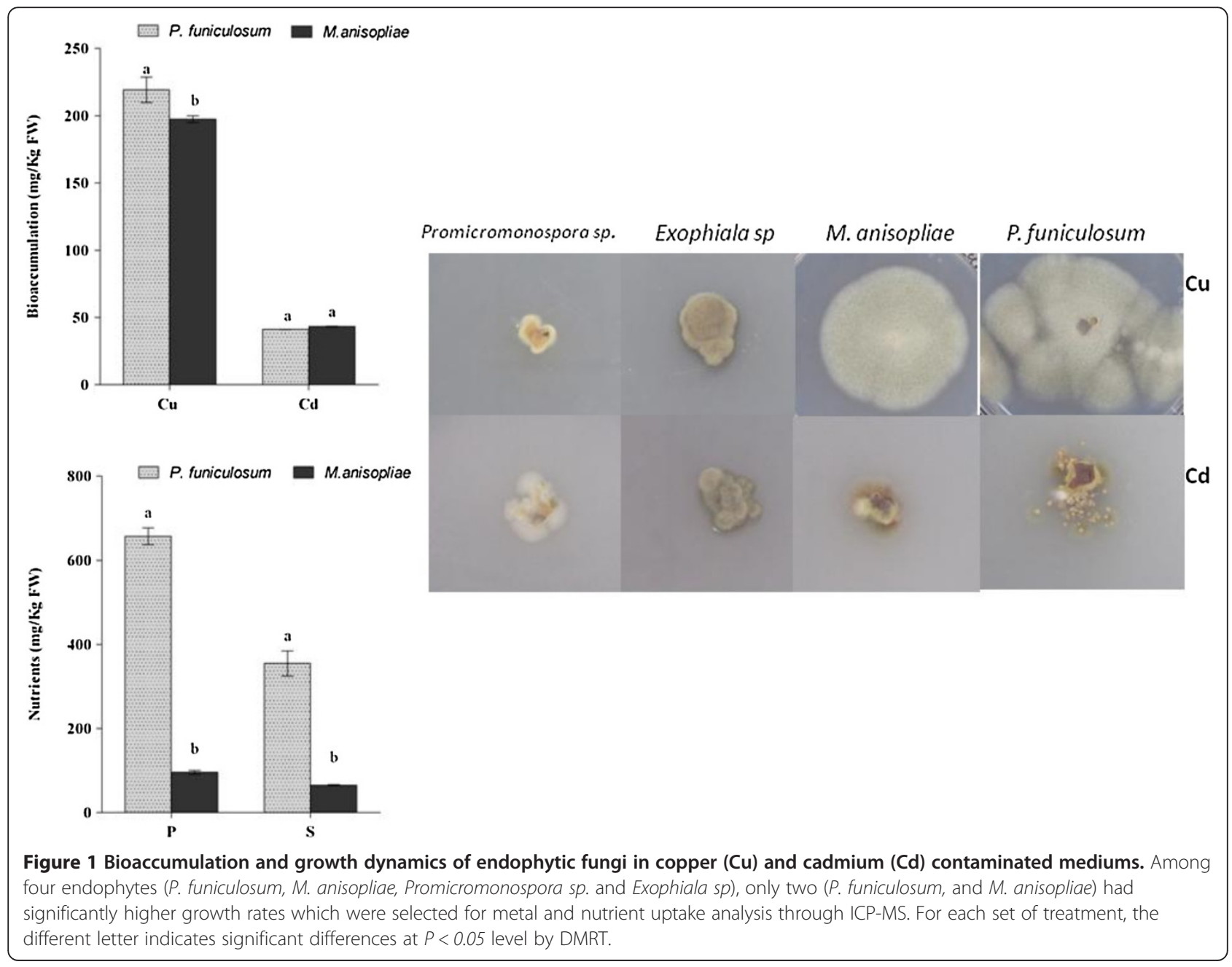


Table 2 Effects of endophyte status on copper stress measured by growth of soybean

\begin{tabular}{ccccc}
\hline Treatments & Association & Shoot length $\mathbf{( c m})$ & Shoot dry weight (g) & Root dry weight (g) \\
\hline \multirow{2}{*}{ Control } & E- & $31.21 \pm 0.64 \mathrm{~b}$ & $6.30 \pm 0.14 \mathrm{~b}$ & $1.10 \pm 0.01 \mathrm{~b}$ \\
\cline { 2 - 5 } & E+ & $36.17 \pm 0.74 \mathrm{a}$ & $7.20 \pm 0.13 \mathrm{a}$ & $3.42 \pm 0.03 \mathrm{a}$ \\
\hline Copper $(100 \mu \mathrm{M})$ & $\mathrm{E}-$ & $27.21 \pm 0.16 \mathrm{~b}$ & $6.05 \pm 0.16 \mathrm{~b}$ & $1.3 \pm 0.06 \mathrm{~b}$ \\
\cline { 2 - 5 } & $\mathrm{E}+$ & $33.25 \pm 0.51 \mathrm{a}$ & $6.96 \pm 0.14 \mathrm{a}$ & $3.16 \pm 0.08 \mathrm{a}$ \\
\hline
\end{tabular}

Values in the table refer to mean of 21 plants/treatment while \pm shows S.E. Means followed by different letter (s) are significantly different $(P<0.05)$ between $\mathrm{E}-$ and $\mathrm{E}+$ as determined by Duncan's multiple-range test.

showed that during normal growth condition, chlorophyll $a$ and total carotenoid content had no significant difference between $\mathrm{E}$ - and $\mathrm{E}+$ plants however, chlorophyll $b$ was significantly higher in $\mathrm{E}+$ than $\mathrm{E}-$. Upon $\mathrm{Cu}$ stress to soybean plants, the $\mathrm{E}+$ plants had significantly higher Chlorophyll $a, b$ and total carotenoid as compared to Eplants. The increased synthesis of photosynthetic pigments was also confirmed by the level of protein metabolism. Total protein content was significantly higher in $\mathrm{E}+$ plants as compared to $\mathrm{E}$ - plants under normal growth and $\mathrm{Cu}$ stress conditions (Figure 3).

\section{Copper uptake and root essential nutrients composition}

To elaborate the metal uptake by the soybean roots, the $\mathrm{Cu}$ content was assessed through ICP-MS. According to analysis, $\mathrm{Cu}$ was not detected in $\mathrm{E}+$ plants grown under normal conditions however the E- plants contained a significantly lower amount of $\mathrm{Cu}$ in roots. Under $\mathrm{Cu}$ stress, a significantly higher $\mathrm{Cu}$ uptake was observed in the non-inoculated control plants (E-) as compared to $P$. funiculosum-inoculated plants (E+; Figure 4). A similar trend was also revealed in the $\mathrm{Cu}$ accumulation in soybean shoots. The E- plants had significantly higher $\mathrm{Cu}$ content in their shoots as compared to $\mathrm{E}+$ during $\mathrm{Cu}$-stress (Figure 4). Furthermore, there was a significant difference between $\mathrm{E}+$ and $\mathrm{E}$ - to remove $\mathrm{Cu}$. From the $\mathrm{Cu}$ quantification, it was also observed that the root parts had higher concentration of $\mathrm{Cu}$ as compared to shoot which suggest endophytic intervention of $\mathrm{Cu}$ transport into shoots via roots (Figure 4). This was also confirmed from the $\mathrm{Cu}$ removal capacity of endophyte-inoculated plants. The result showed that the $\mathrm{Cu}$ tolerance rate was significantly higher in $\mathrm{E}+(81.3 \%)$ as compared to $\mathrm{E}$ - $(43.4 \%)$. The transport index was also significantly different between $\mathrm{E}+$ and E-. The P. funiculosum inoculated plants had lower $\mathrm{Cu}$ transport rate $(37.8 \%)$ as compared to E(66.1\%). It indicates that endophytic fungal-association has mitigated the $\mathrm{Cu}$ induced abiotic stress.

Essential nutrients i.e. sulfur and phosphorus uptake from the soil by roots was significantly higher in $\mathrm{E}+$ plants as compared to E- plants. Phosphorus $(\mathrm{P})$ is a major nutrient for plant growth and reproduction. Phosphorus content was significantly higher in the roots of $\mathrm{E}+$ plants under normal and $\mathrm{Cu}$ stress conditions as compared to E- plants (Figure 4). Current findings suggest that $P$. funiculosum helped the soybean plants in the availability of P even during stress conditions. Sulfur, being taken from soil into plant tissues, plays essential role in building parts of plant proteins and important amino acids. Significantly higher contents of sulfur was found in the roots tissues of $P$. funiculosum-associated plants as compared to non-inoculated control plants under normal and $\mathrm{Cu}$ stress conditions (Figure 4). Calcium $(\mathrm{Ca})$ in plant's roots plays a pivotal role in plant growth and response to abiotic stress and microbial association [26]. Our results showed that endophyte $P$. funiculosum association significantly activated Ca signaling in the roots of soybean plant as compared to control (Figure 4). The same trend was also observed under $\mathrm{Cu}$ stress. Potassium (K) content was also significantly higher in $\mathrm{E}+$ plants than $\mathrm{E}$ - plants under normal and $\mathrm{Cu}$ stress conditions.

\section{Effects on electrolytes, lipid peroxidation and reduced glutathione}

The electrolytes release from plant tissues was not significantly different between $\mathrm{E}+$ and $\mathrm{E}$ - plant under normal conditions. However, when soybean plants were exposed to $\mathrm{Cu}$ stress, the rate of electrolytes formation was significantly higher in non-infected soybean plants as compared to P. funiculosum infected plants (Figure 5). The results suggest that endophyte-association reduced the functional membrane damage under $\mathrm{Cu}$ stress. This was also in conformity with lipid peroxidation of leave tissues of endophyte-associated plants. It is known that with excursion of stress conditions the peroxides of polyunsaturated fatty acids generates malondialdehyde (MDA) which is the most abundant individual aldehydic lipid-layer breakdown product [27]. Normally abiotic stress induces the rate of lipid peroxidation by producing higher amount of MDA. However, this trend was minimized by the endophytesymbiosis with soybean plants as compared to control plants during $\mathrm{Cu}$ stress (Figure 5). Additionally, the $\mathrm{Cu}$ toxicity also develops oxidative stress inside plant tissues which is counteracted by the recruitment of antioxidants like glutathione. Reduced glutathione (GSH) was extensively synthesized in endophyte-inoculated plants than the non-inoculated ones under $\mathrm{Cu}$ stress and normal growth conditions (Figure 5). 

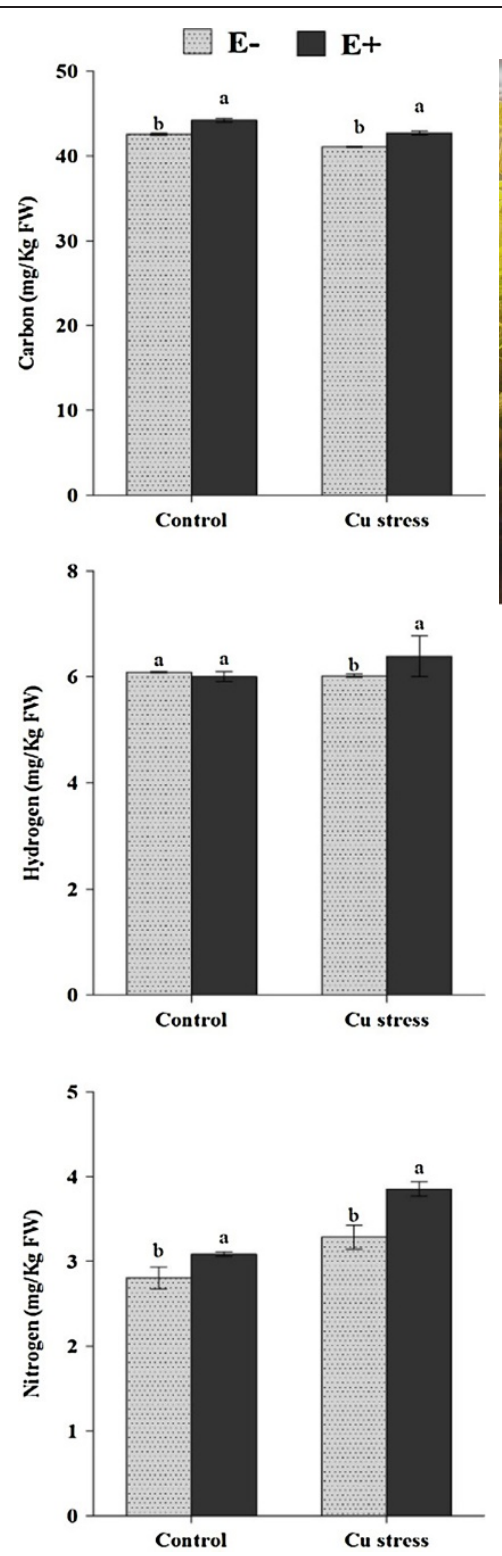

Figure 2 Effect of copper $(\mathrm{Cu})$ stress on soybean plant growth and essential macronutrient assimilation with (E+) or without (E-) the inoculation of endophyte $P$. funiculosum. $E-C u^{\prime}$ and ' $E+C u^{\prime}$ refer to plants treated with copper with or without the presence of endophyte respectively. The experiment was replicated three times with three replications each time while each treatment contained 21 plants. For each set of treatment, the different letter indicates significant differences at $P<0.05$ level by DMRT.

\section{Regulation of free amino acid and abscisic acid in host-plants under Cu stress}

Plants synthesize its amino acids using nitrogen and related intermediaries obtained through roots from the soil [28]. The free amino acid synthesis was higher during endophyte-association under normal growth conditions as compared to endophyte-free counterpart. The aspartic acid (Asp), threonine (Thr), glutamine (Glu), leucine (Leu), methionine (Met) and proline (Pro) were significantly higher in $\mathrm{E}+$ plants than E- under normal conditions (Figure 6). The other amino acids were either similar or in-significantly higher in $E+$ than E- plants. Free amino acid production was further stimulated by $\mathrm{Cu}$ stress in the presence of endophyte $(\mathrm{SE}+)$. The level of Pro, Glu, and Leu was significantly higher in $P$. funiculosum associated plants as compared to noninfected (SE-) plants.

Endogenous stress-responsive phytohormone abscisic acid (ABA) was accumulated upon exposure to abiotic stresses including heavy metal. The control plants (E-) when treated with $\mathrm{Cu}$ accumulated significantly higher level of ABA. Conversely, when endophyte-infected 

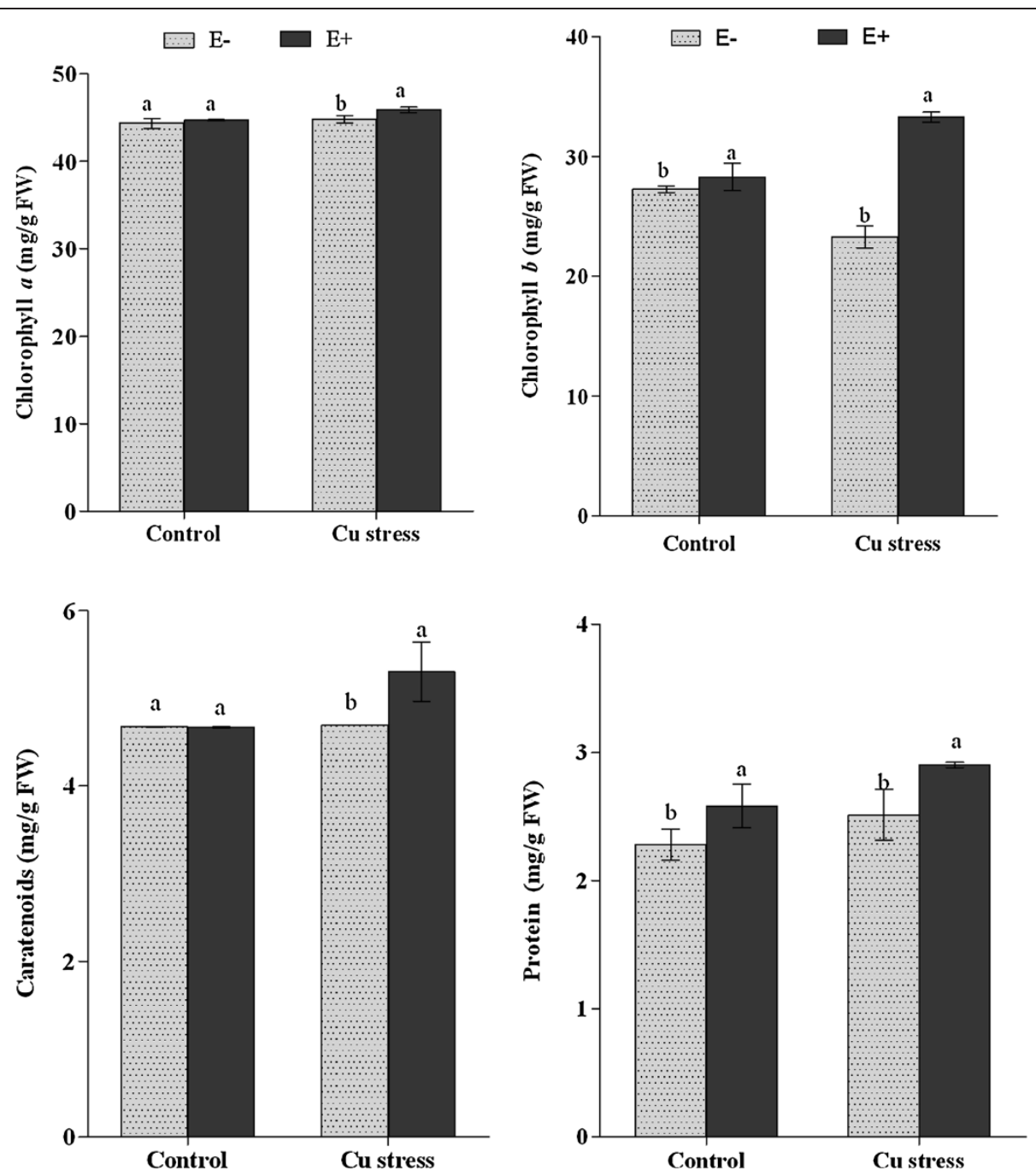

Figure 3 Influence of copper stress on the chlorophyll, caratenoids and protein contents of soybean plants inoculated with endophyte. E-Cu' and 'E + Cu' refer to plants treated with copper with or without the presence of endophyte respectively. For each set of treatment, the different letter indicates significant differences at $P<0.05$ level by DMRT.

plants were treated with $\mathrm{Cu}$, the ABA level was observed significantly lower as compared to non-inoculated control plants (Figure 7).

\section{Discussion}

In the present study, bioactive endophytic fungal strains were initially screened for their growth potential in $\mathrm{Cd}$ and $\mathrm{Cu}$ polluted mediums. The results suggested that $P$. funiculosum had higher growth rate as compared to the other three M. anisopliae, Promicromonospora sp. and Exophiala sp endophytes. P. funiculosum had higher potential to dwell in excessive $\mathrm{Cu}$ than $\mathrm{Cd}$. The role of endophytic fungi has been recently elucidate by $\mathrm{Li}$ et al. [23] however, this more concentrate on the bacterial strains than fungal strains. Few endophytes like Microsphaeropsis, Mucor, Phoma, Alternaria, Peyronellaea, Steganosporium, and Aspergillus have been known to grow well in polluted medium and protect plants from adverse effects of metal stress [23]. Very little has been known about endophytic Penicillium and its role in host-plant resistant to metal stress. Some strains of Penicillium janthinellum and $P$. simplicissimum have been found to grow well in high $\mathrm{Cu}$ medium [29], suggesting that they bears higher biosorption capacity against $\mathrm{Cu}$. Previous studies showed that some strains of Penicillium can extend tolerance to host plants against metal toxicity. For example, strains of $P$. janthinellum and $P$. simplicissimum reduced the aluminum and zinc toxicity as it produced citric acid [30]. Similarly, an isolate of Penicillium sp. bioaccumulated $\mathrm{Cd}$ during incubation period [31]. The findings of studies suggest that strains/species of Penicillium can mitigate the $\mathrm{Cd}$ and other metal-related toxicity, which can be 

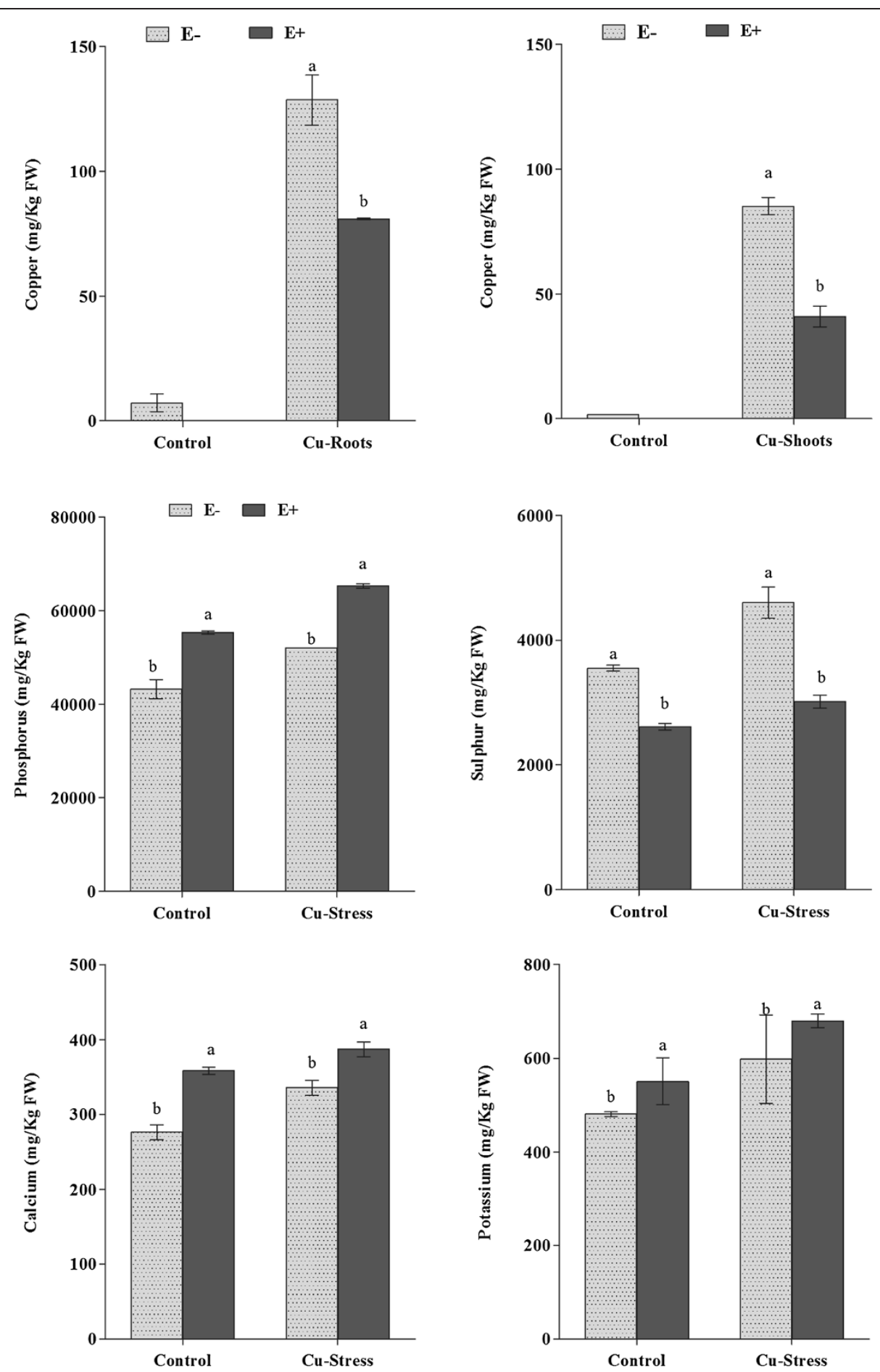

Figure 4 Accumulation of copper inside soybean roots and its impact on the composition of essential nutrients in association with endophyte $(\mathbf{E}+)$. For each set of treatment, the different letter indicates significant differences at $P<0.05$ level by DMRT.

attributed to their potential to produce bioactive metabolites or enzymes [30,31]. Previously, it was noted that P. funiculosum produce bioactive gibberellins which can contribute to the ability of a fungus to convert the toxic metal into stable complexes [31]. A similar effect of stabilizing the negative effects of sodium chloride toxicity was also observed when this endophyte was inoculated to soybean plants [15].

Association of endophytic fungi with crop plant can increase plant fitness under abiotic stress conditions 


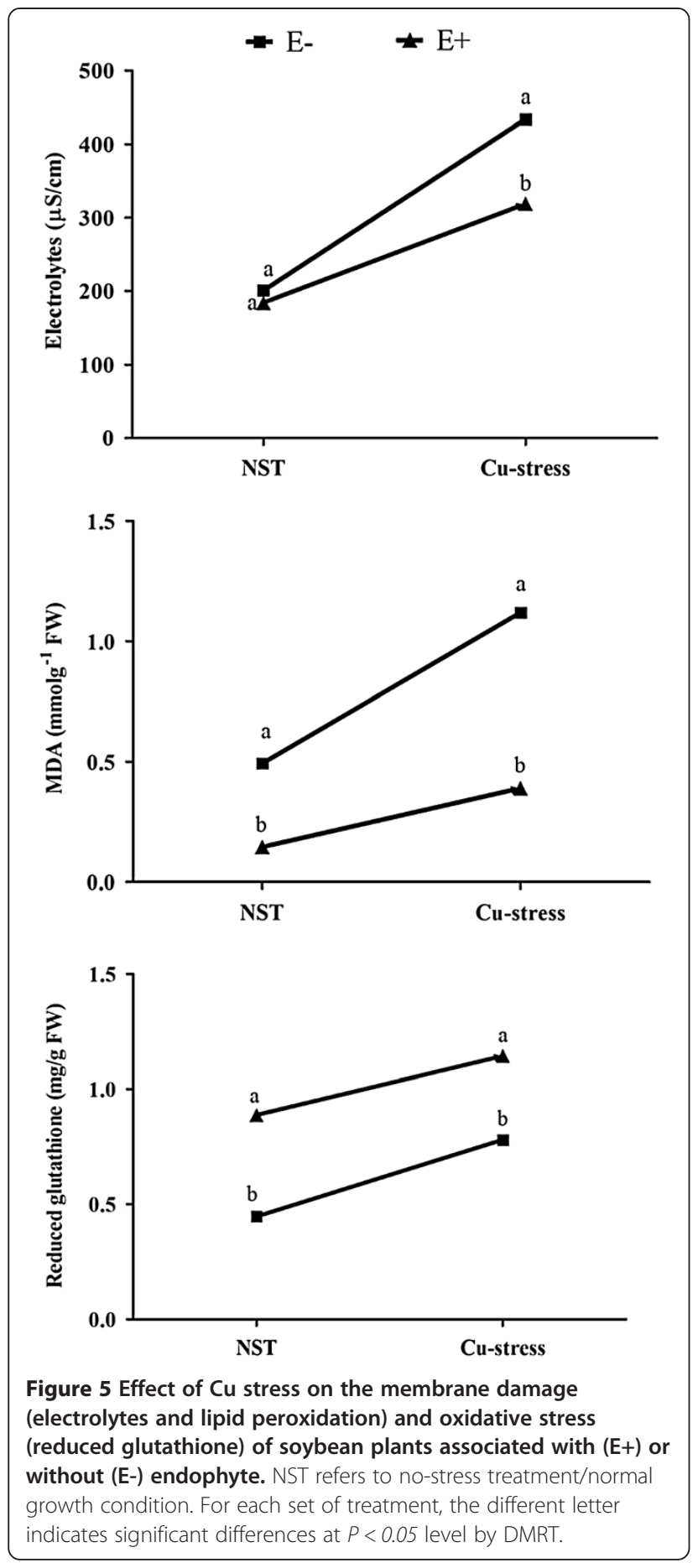

$[11,13,32]$. The secretion of plant growth regulating compounds by the endophyte probably is the mechanism responsible for the enhancement of plant growth $[11,13]$. Since the culture filtrate of $P$. funiculosum showed the presence of physiologically active gibberellins [15], therefore, we inoculated soybean plants with the culture medium including propagules of the endophyte. Application of such phytohormones producing endophytes can counteract adverse effects of abiotic stresses on plant growth as shown by Khan et al. [15]. Indeed the fungal associations have ameliorated the growth of Arabidopsis [8], Rapes [10], Solanum nigrum [22], Festuca arundinacea and Festuca pratensis [6], Lolium arundinaceum [21] under various $\mathrm{Cd} / \mathrm{Ni}$ stresses. $\mathrm{Cu}$ has been known to induce reduction in photosynthesis, water and nutrient uptake. Plants grown in soil containing high levels of $\mathrm{Cu}$ show visible symptoms of injury reflected in terms of chlorosis, growth inhibition, browning of root tips, and finally death [33]. In addition, $\mathrm{Cd}$ causes decreased stomatal conductance [34] which affect photosynthetic rates. In present study, we observed that endophytic-fungal association activated the growth of soybean plants by improving plant biomass and synthesizing high chlorophyll, carotenoid and protein to counteract the $\mathrm{Cu}$ stress. The ameliorative impacts of endophyte-association were also rectified by the shoot's carbon and hydrogen content after excursion of $\mathrm{Cu}$ stress. A similar effect was also observed when Neotyphodium endophytes were colonized to various grass species. Its symbiosis protected the host plants from metal toxicity of aluminum [19], cupper [20] and zinc [35].

In addition to plant biomass loss, excessive $\mathrm{Cu}$ pollution also reduces the availability and uptake of essential micronutrients in both root and shoot [4]. Conversely in present results, the endophyte-infection increased the $\mathrm{K}$, $\mathrm{Ca}$ and $\mathrm{P}$ contents in root tissues as compared to control (E-) plants under $\mathrm{Cu}$ stress. Besides potassium's role in plant cellular metabolism, it plays essential part in oxidative stress responses by helping the synthesis of glutathione (GSH) which is associated with stress tolerance [36]. In present study, the GSH level was significantly high in $\mathrm{E}+$ plants than E- under $\mathrm{Cu}$ stress. These results suggest that copper alters the equilibrium between synthesis and utilization of GSH either due to its antioxidant role or by serving as a precursor in the synthesis of phytochelatins [36]. Similarly, our results showed that Ca content was high in the presence of endophyte during stress. Ca has an essential role in plant growth and signal transduction related to many biotic and abiotic circumstances [26,37]. To minimize $\mathrm{Cu}$ toxicity and rescue plant productivity, it is essential for plants to uptake freely available mineral nutrients (such as $\mathrm{Ca}$ ). This also indicates that increased endophytic-fungal colonization with soybean plants resulted in activation of Ca signaling to counteract stress. Previously, Kováčik et al. [4] indicated activation of $\mathrm{Ca}$ upon $\mathrm{Cu}$ stress. Among nutrients, phosphate is major macronutrient for plants to sustain cellular metabolism whilst availability of free phosphate can extend higher growth and metabolism in host plants [38-40]. Microorganisms are major contributor in this function. Previously, we found that $P$. funiculosum had high phosphate (P) solubilization potential [15] and hence in present study, the same helped the host soybean plants to accumulate high $\mathrm{P}$ as compared to 


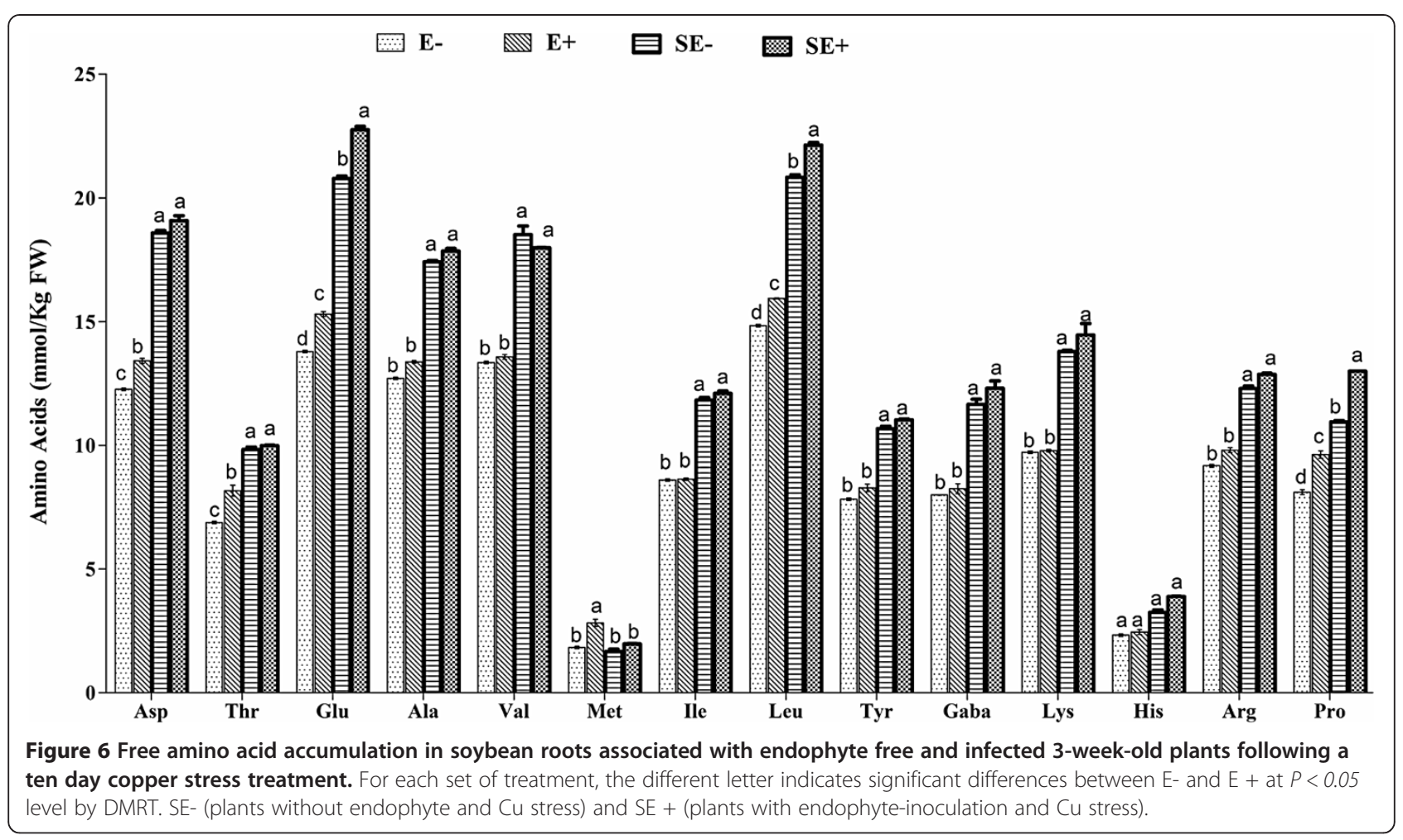

endophyte-free plants during $\mathrm{Cu}$ stress. These ameliorative effects on soybean plants were also rectified by the reduced levels of $\mathrm{Cu}$ accumulation in the roots of $\mathrm{E}+$ plants as compared to E- plants. It further suggests that endophyte might have higher sorption of $\mathrm{Cu}$ during association with host-soybean plants thus accumulating low level of $\mathrm{Cu}$ inside roots. However, the in-depth mechanism is still unclear.

It is evident that $\mathrm{Cu}$ toxicity to plants also results in membrane damage due to generation of reactive oxygen species. During stress, the malondialdehyde (MDA) is generated which indicates impact on plant membrane [27]. The significantly higher level of MDA in E- plants shows injury to functional membrane during $\mathrm{Cu}$ stress. This was also confirmed by the high electrolytic leakage of E- plants. However, during symbiosis with endophyte, most of the adverse effects of $\mathrm{Cu}$ toxicity were minimized which suggests the ameliorative function of endophyte. Excessive $\mathrm{Cu}$ toxicity, on the other hand, adversely affect the physiologically important free amino acid metabolism [41] because it lies at the crossroad between nitrogen assimilation, carbon fixation and secondary metabolism $[28,42]$. Current results showed reduced amino acid metabolism in E- plants as compared to $\mathrm{E}+$ plants during $\mathrm{Cu}$ stress, which suggest rescuing role of endophyteassociation to enhance cellular metabolism and improve plant growth. E + plants had significantly higher Pro, Glu, and Leu under $\mathrm{Cu}$ stress. Proline (Pro) has been widely known to act as osmo-protectant during abiotic stress

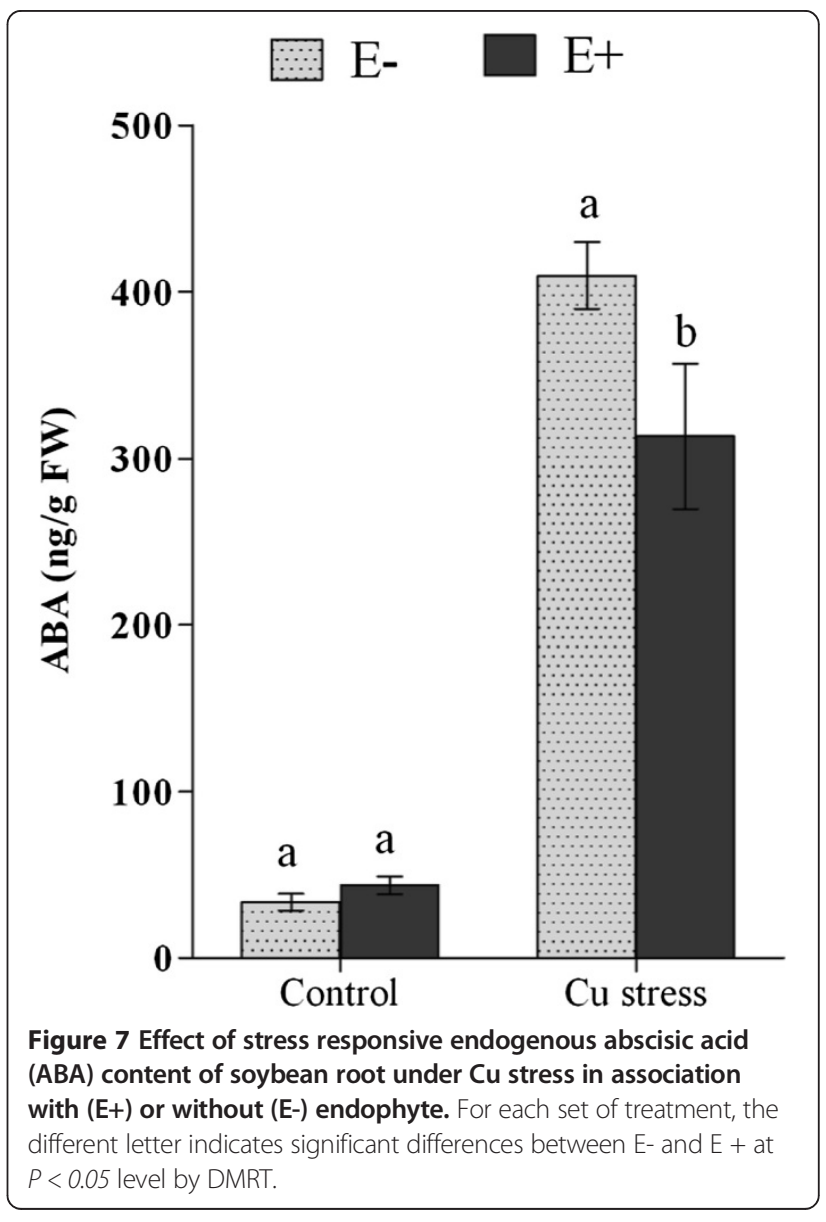


condition whilst its accumulation in $\mathrm{E}+$ plants showed restoration of growth against stress. Current findings of higher nitrogen assimilation by $\mathrm{E}+$ plants further corroborate with the fact that even in stress conditions, the glutamate cycle and amino acid inter-conversion were not significantly affected as compared to E- plants.

Heavy metals such as $\mathrm{Cu}$ toxicity to the plants also increase the biosynthesis of endogenous abscisic acid (ABA) (see review of Tuteja [43] and reference therein). Higher ABA may also inhibit the photosynthesis rate as stress perception causes the closure of stomata to avoid dehydration. This further reduces leaf area and plant shoot length with the passage of stress period just like E- plants under stress. In present study, ABA level was significantly lower in E + plants as compared to E- plants under $\mathrm{Cu}$ stress. While after ten days of stress period, the $\mathrm{E}+$ plants still maintained higher growth as was noticed during the quantification of free amino acids, essential nutrients and ABA. Previous studies suggest that fungal inoculation can increase ABA content in leaves and roots as compared to non-inoculation control plants [43-46]. Contrarily, current findings showed that endophyteassociated soybean plants had reduced ABA as compared to control plants during stress. This altered level of ABA confirms the findings of Mauch-Mani and Mauch [45] and Jahromi et al., [46], who observed low level of ABA under stress and fungal-association. This could be due the gibberellins secretion potential of the endophytes because the non-gibberellins producing strains did not contributed towards the bioaccumulation of $\mathrm{Cd} / \mathrm{Cu}$ during the screening experiment. A similar behavior of endophytes was also observed in some of the previous studies [13-15]. Sharp et al. [47] reported similar results with flacca mutant, however, in present study, the phosphate solubilization and gibberellins production potential of endophyte $P$. funiculosum has not only reprogram the plant growth but also helped the soybean plants to tolerate $\mathrm{Cu}$ stress.

\section{Conclusion}

The findings of the present study suggest that endophytes such as $P$. funiculosum can not only improve plant biomass but also resist to the toxic effects of metal contamination. Such beneficial impacts are due to their potential to secrete bioactive gibberellins as noted previously which might help in converting the metal into stable complexes. This could be also attributed to the reduced level of metal inside roots and shoot of soybean plants in symbiosis with endophyte. Influencing soybean plant's root physiology whilst delineating ameliorative impacts on shoot growth is an ideal strategy to achieve the dual uses of increased crop productivity as well as reduced toxic effects of copper pollution. However, it is also essential to understand the in vivo mechanisms by which the gibberellins producing endophytes reduce the metal toxicity.

\section{Methods}

\section{Endophyte growth and heavy metal resistant strain}

P. funiculosum, M. anisopliae, Promicromonospora sp. and Exophiala sp (Table 1) were isolated from the roots of soybean/cucumber plants and were identified through DNA extraction, PCR techniques, sequencing and phylogenetic analysis of Internal Transcribed Spacer (ITS) and Large Sub-unit (LSU) rDNA. The universal primers used for this purpose were: ITS-1 (5'-TCC GTA GGT GAA CCT GCG G-3') and ITS-4 (5'-TCC TCC GCT TAT TGA TAT GC-3') and LROR (F) (5'-ACC CGC TGA ACT TA AGC-3') and TW13(R) (5'-GGT CCG TGT TTC AAG ACG-3') as described by Redman et al. [13].

The isolated strains were grown in potato dextrose agar (PDA) having $50 \mu \mathrm{M}$ concentration of cadmium $\left[\mathrm{Cd}_{3}\left(\mathrm{PO}_{4}\right)_{2}\right]$ and copper $\left(\mathrm{CuSO}_{4}\right)$ respectively. After 10 days of incubation $\left(28^{\circ} \mathrm{C}\right.$ in darkness), the growth rate of endophytes was measured as describe by Pan et al. [25] and Alhamed and Shebany [18]. Each treatment had five replications to assess the growth zone development. On the basis of results, the bioactive strain was grown in the Czapek broth $(500 \mathrm{ml}$ containing $1 \%$ glucose, $1 \%$ peptone, $0.05 \% \mathrm{KCl}, 0.05 \% \mathrm{MgSO}_{4} .7 \mathrm{H}_{2} \mathrm{O}$, and $0.001 \%$ $\mathrm{FeSO}_{4} .7 \mathrm{H}_{2} \mathrm{O} ; \mathrm{pH} 7.3 \pm 0.2$ ) and incubated for 10 days at $30^{\circ} \mathrm{C}$ under shaking conditions $(120 \mathrm{rpm})$.

\section{Plant growth and heavy metal stress}

Soybean (Glycine max L. var. hwangkeumkong) seeds (moisture content 6\%; germination $85 \%$ ) were donated by Prof. Dong-Jang Lee (School of Applied Biosciences, Kyungpook National University, Republic of Korea). Seeds were surface-sterilized by immersing in $20 \%$ ethanol for $30 \mathrm{sec}$ and then in $0.2 \%$ solution of $\mathrm{Hg}_{2} \mathrm{Cl}_{2}$ for $2 \mathrm{~min}$, followed by several rinses with sterile double distilled water to remove disinfectant [48]. The sterilized seeds were incubated $\left(28^{\circ} \mathrm{C}\right.$ and relative humidity of $\left.60 \%\right)$ for $24 \mathrm{~h}$ to obtain an equal germination (moisture content $78.1 \%$ at $26^{\circ} \mathrm{C}$ in darkness). To assess the interaction of plant-microbe- metal, the germinated seeds were sown in autoclaved pots $(30 \times 15 \mathrm{~cm} ; 1 \mathrm{Kg} /$ pot at $121^{\circ} \mathrm{C}$ for $15 \mathrm{~min}$ ) containing the substrate composed of: peat moss (10-15\%), perlite (35-40\%), coco-peat (45-50\%) and zeolite (6-8\%) with macro-nutrients present as: $\mathrm{NH}_{4} \sim 0.09 \mathrm{mg} \cdot \mathrm{g}^{-1} ; \mathrm{NO}_{3} \sim 0.205 \mathrm{mg} \cdot \mathrm{g}^{-1}$; $\mathrm{P}_{2} \mathrm{O}_{5} \sim 0.35 \mathrm{mg} \cdot \mathrm{g}^{-1}$ and $\mathrm{K}_{2} \mathrm{O} \sim 0.1 \mathrm{mg} \cdot \mathrm{g}^{-1}$ [49].

The heavy metal-resistant endophytic strain, grown in Czapek broth $(20 \mathrm{ml}$ for each pot containing 2-3 $\mathrm{g}$ of fungal propagules) was added to the pots to initiate the infection process of soybean roots. The control plants only received endophyte-free Czapek broth $(20 \mathrm{ml} /$ pot $)$ using the same recipe and conditions as mention in previous section. Thus, soybean plants and endophyte were grown together for three weeks in the growth chamber (day/night cycle: $14 \mathrm{~h} ; 28^{\circ} \mathrm{C} / 10 \mathrm{~h} ; 25^{\circ} \mathrm{C}$; relative 
humidity $60-70 \%$; light intensity $1000 \mu \mathrm{Em}^{-2-}$ s Natrium lamps) and irrigated with distilled water. The experimental designed included endophyte-free control plants with or without metal stress and endophyte-infected plants with or without metal stress. Three weeks grown soybean plants with and without endophytic fungal association were applied with copper stress $\left(\mathrm{CuSO}_{4}\right) 100 \mu \mathrm{M}$ for 10 days. The $\mathrm{Cu}$ solution $(100 \mathrm{ml}$ per pot i.e. $16 \mathrm{mg} / \mathrm{Kg}$ $\mathrm{Cu}$ in each pot filled with $1 \mathrm{Kg}$ autoclaved soil) was applied after every $24 \mathrm{~h}$ for 10 days. Each time plants were irrigated before $\mathrm{Cu}$ treatment to avoid leaching. Thus, the final concentration of $\mathrm{Cu}$ remained the same throughout the experiment. The experiment was replicated three times with three replications each time while each treatment contained 21 plants.

After stress period, the shoot length was measured while the shoot and root biomass of soybean plants were measured by drying them in oven at $65^{\circ} \mathrm{C}$ for $72 \mathrm{~h}$. For photosynthetic pigments, lipid peroxidation and antioxidant, fresh plants samples were used while for elemental/metal and plant hormonal analysis, plant samples were freeze dried for 4-5 days (Virtis Freeze Dryer, Gardiner, NY, USA). All the readings were taken in triplicate. To determine the plant translocation ability of metal via root to shoot, the transport index $\left[\left(\mathrm{Cu}\right.\right.$ shoot $\mathrm{mg} \mathrm{Kg}^{-1} / \mathrm{Cu}$ root $\left.\mathrm{mg} \mathrm{Kg}^{-1}\right) \times$ 100] was calculated as suggested by Soleimani et al. [6]. While the $\mathrm{Cu}$ removal or tolerance capacity was measured through this formula:

$$
\left[\frac{\mathrm{Cu} \text { shoot } \times \text { shoot weight }+\mathrm{Cu} \text { root } \times \text { root weight }}{\text { Total } \mathrm{Cu} \text { added } / \text { plot }}\right] \times 100
$$

\section{Determination of photosynthetic pigments}

Photosynthetic pigments were extracted from leaves of soybean plants ground with $80 \%$ acetone. The chlorophylls and carotenoid were estimated according to the method of Lichtenthaler [50]. The absorbance for chlorophyll $\boldsymbol{a}$ and $\boldsymbol{b}$ and carotenoid was recorded at 663, 645 and $470 \mathrm{~nm}$, respectively. Chlorophyll content was calculated using the following formulae:

$$
\begin{aligned}
& \text { - Chlorophyll } a(\mathrm{mg} / \mathrm{g} \mathrm{FW}) \\
& \qquad=\left[\left\{\left(12.7 \times \mathrm{A}_{663}\right)-\left(2.69 \times \mathrm{A}_{645}\right)\right\} / 1,000 \times \mathrm{W}\right] \mathrm{xV} \\
& \text { - Chlorophyll } b(\mathrm{mg} / \mathrm{g} \mathrm{FW}) \\
& \qquad=\left[\left\{\left(22.9 \times \mathrm{A}_{645}\right)-\left(4.68 \times \mathrm{A}_{663}\right)\right\} / 1,000 \times \mathrm{W}\right] \mathrm{xV} \\
& \text { - Total carotenoid content } \\
& =\left(1,000 \mathrm{~A}_{470}-1.82 \text { chlorophyll } a-85.02 \text { chlorophyll } b\right) / 198
\end{aligned}
$$

Where $W$ is the fresh weight and $V$ is the extraction volume.

\section{Determination of electrolytes, lipid peroxidation and reduced glutathione}

Leaf electrolyte (E) was determined as reported by González and González-Vilar [51]. Fresh leaves (200 mg) samples were cut into $5 \mathrm{~mm}$ length and placed in test tubes containing $10 \mathrm{ml}$ deionized distilled water. The tubes covered with plastic caps were placed in a water bath at a constant temperature of $30^{\circ} \mathrm{C}$. After $2 \mathrm{~h}$ the initial electrical conductivity $\left(\mathrm{EC}_{1}\right)$ was measured using an electrical conductivity meter. The samples were kept at $121^{\circ} \mathrm{C}$ for $20 \mathrm{~min}$ to completely kill the tissues and release all electrolytes. The samples were then cooled to $25^{\circ} \mathrm{C}$ and final electrical conductivity $\left(\mathrm{EC}_{2}\right)$ was measured. The electrolytes released were estimated using formula: $\mathrm{E}=\mathrm{EC}_{1} / \mathrm{EC}_{2}$. The experiment was repeated three times and results were expressed in $\mu \mathrm{S} / \mathrm{cm}$.

To confirm the electrolytes released and damages to the plant membrane after $\mathrm{Cu}$ toxicity, extent of lipid peroxidation was determined by the method of Ohkawa et al. [52]. For this assay, $0.2 \mathrm{ml} 8.1 \%$ sodium dodecyl sulphate, $1.5 \mathrm{ml} \mathrm{20 \%}$ acetic acid $(\mathrm{pH} 3.5)$ and $1.5 \mathrm{ml}$ $0.81 \%$ thiobarbituric acid aqueous solution were added in succession in a reaction tube. Then $0.2 \mathrm{ml}$ tissue homogenate extracted with $10 \mathrm{mM}$ phosphate buffer ( $\mathrm{pH}$ 7.0) was added. The mixture was heated in boiling water for $60 \mathrm{~min}$. After cooling to room temperature, $5 \mathrm{ml}$ butanol: pyridine $(15: 1 \mathrm{v} / \mathrm{v})$ were added. The upper organic layer was separated and the optical density of the resulting pink color was recorded at $532 \mathrm{~nm}$ using spectrophotometer. Tetramethoxypropane was used as an external standard. The level of lipid peroxides was expressed as micro moles of malondialdehyde (MDA) formed/g tissue weight. The experiments were repeated three times.

To determine reduced glutathione (GSH), fresh leaves tissues $(100 \mathrm{mg}$ ) were ground in $3 \mathrm{ml} 5 \%$ (v/v) trichloroacetic acid using chilled mortar and pestle. The homogenates were centrifuged at 2,500 $\times g$ for $15 \mathrm{~min}$ at $-4^{\circ} \mathrm{C}$. The supernatants were analyzed for the content of reduced glutathione (GSH) according to the method of Ellman [53]. Supernatant $(0.1 \mathrm{ml})$ was added to $3.0 \mathrm{ml}$ $150 \mathrm{mM} \mathrm{NaH} \mathrm{PO}_{4}$ (pH 7.4) containing $0.5 \mathrm{ml}$ of Ellman's reagent. The mixture was incubated at $30^{\circ} \mathrm{C}$ for $5 \mathrm{~min}$. Absorbance was determined at $412 \mathrm{~nm}$ and the GSH concentration was calculated by a standard curve.

\section{Determination of $\mathrm{Cu}$ and essential nutrients uptake}

In the screening experiment of metal and endophyte, the grown endophyte pads were detached from PDA plates and subjected to Inductively Coupled Plasma Mass Spectrometry (ICP-MS; Optima 7900DV, Perkin-Elmer, USA) analysis of $\mathrm{Cd} / \mathrm{Cu}$ to differentiate and identify higher metal accumulating strain [54]. Similarly, after metalplant-microbe interaction, the metal-treated soybean roots and shoot associated with or without endophytes were assessed for metal uptake and its influence on the accumulation of essential nutrients. The plant samples were immediately shifted into liquid nitrogen and freeze 
dried $\left(-55^{\circ} \mathrm{C}\right.$; Virtis Freeze Dryer, Gardiner, USA) for 3-4 days. The contents of $\mathrm{Cu}$ and essential nutrient like phosphorus, sulfur, potassium and calcium were determined by ICP-MS while carbon, hydrogen and nitrogen contents in the shoot parts were determined by the elemental analyzer (Flash2000, ThermoFisher Scientific Inc., Waltham, MA, USA).

\section{Free amino acid extraction and quantification}

All the treated soybean plants roots were immediately shifted to liquid nitrogen and then kept at $-80^{\circ} \mathrm{C}$. The roots parts were freeze dried $\left(-55^{\circ} \mathrm{C}\right.$; Virtis Freeze Dryer, Gardiner, NY, USA). The root samples (100 mg) were extracted with $2 \mathrm{ml} \mathrm{10 \%} \mathrm{trichloroacetic} \mathrm{acid} \mathrm{with} \mathrm{gentle}$ agitation on a shaker $\left(110^{\circ} \mathrm{C}\right.$ for $\left.24 \mathrm{~h} ; 50 \mathrm{rpm}\right)$. The filtrate was dried and dissolved in $0.02 \mathrm{~N} \mathrm{HCl}$ to obtain supernatant through centrifugation (10,000 rpm for $15 \mathrm{~min})$. The amino acid compositions were then obtained by automatic analysis algorithm of the amino acid automatic analyzer. The amino acid analyzer (HITACHI L-8900, Japan) attached to HITACHI HPLC (packed column with ion-exchanging resin - No. 2622 PF; $4.6 \times 60 \mathrm{~mm}$ ) and UV detector (VIS1: $570 \mathrm{~nm}$, VIS2: $440 \mathrm{~nm}$ ) was used for analysis of free amino acids. Wako L-8500 buffer solution PF-1, 2, 3, 4 and RG were used as mobile phase. About $20 \mu \mathrm{l}$ of each sample was injected. Free amino acids were determined by using Ninhydrin reagent set (Wako Chemical Inc, Japan). All samples were run in triplicates and expressed in $\mathrm{mmol} / \mathrm{Kg}$ fresh weight.

\section{Abscisic acid extraction and quantification}

The endogenous abscisic acid (ABA) content was quantified from the freeze dried samples by following the protocols of Kamboj et al. [55]. Plant samples were extracted with $30 \mathrm{ml}$ of extraction solution containing 95\% isopropanol, 5\% glacial acetic acid, and $20 \mathrm{ng}$ of $\mathrm{Me}-\left[{ }^{2} \mathrm{H}_{6}\right]-\mathrm{ABA}$. The filtrate was concentrated by a rotary evaporator. The residue was dissolved in $4 \mathrm{ml}$ of $1 \mathrm{~N}$ sodium hydroxide solution, and then washed three times with $3 \mathrm{ml}$ of methylene chloride to remove lipophilic materials. The aqueous phase was brought to approximately $\mathrm{pH} 3.5$ with $6 \mathrm{~N}$ hydrochloric acid and partitioned three times into ethyl acetate (EtOAc). EtOAc extracts were then combined and evaporated. The dried residue was dissolved in phosphate buffer $(\mathrm{pH} 8.0)$ and then run through a polyvinylpolypyrrolidone (PVPP) column. The phosphate buffer was adjusted to $\mathrm{pH} 3.5$ with $6 \mathrm{~N} \mathrm{HCl}$ and partitioned three times into EtOAc. EtOAc extracts were combined again and evaporated. The residue was dissolved in dichloromethane $\left(\mathrm{CH}_{2} \mathrm{Cl}_{2}\right)$, and passed through a silica cartridge (Sep-Pak; Water Associates, Milford, Massachusetts, USA) which was pre-washed with $10 \mathrm{ml}$ of diethyl ether: methanol (3:2, v/v) and $10 \mathrm{ml}$ of dichloromethane. ABA was recovered from the cartridge by elution with $10 \mathrm{ml}$ of diethyl ether $\left(\mathrm{CH}_{3}-\mathrm{CH}_{2}\right)_{2} \mathrm{O}$ : methanol $(\mathrm{MeOH})(3: 2, \mathrm{v} / \mathrm{v})$. The extracts were dried and methylated by adding diazomethane for GC/MS-SIM (6890 N network GC system, and 5973 network mass selective detector; Agilent Technologies, Palo Alto, CA, USA) Additional file 1: Table S1 analysis. For quantification, the Lab-Base (ThermoQuset, Manchester, UK) data system software was used to monitor responses to ions of m/e 162 and 190 for Me-ABA and 166 and 194 for $\mathrm{Me}-\left[{ }^{2} \mathrm{H}_{6}\right]$-ABA.

\section{Statistical analysis}

To identify significant effects between the treatments and control with or without stress conditions and endophyte, Duncan's multiple range tests (DMRT) was adopted by using Statistic Analysis System (SAS 9.1, USA) $(P<0.05)$. The mean, standard error and the graphical representation was done through Graph Pad Prism software (version 5.0, San Diego, California USA).

\section{Additional file}

Additional file 1: Table S1. GC-MS conditions used for analysis and quantification of the plant endogenous ABA.

\section{Competing interests}

The authors declare that they have no competing interest.

\section{Authors' contribution}

ALK planned, designed and conducted the experiments. IJL performed phytohormonal quantification and amino acid analysis. ALK and IJL both contributed in writing this manuscript. Both authors read and approved the final manuscript.

\section{Acknowledgment}

The present research work was funded by the Eco-Innovation Project, Korean Government's R \& D program on Environmental Technology and Development, Republic of Korea.

\section{Author details}

'Department of Biological Sciences \& Chemistry, University of Nizwa, Nizwa 616, Sultanate of Oman. ${ }^{2}$ School of Applied Biosciences, College of Agriculture and Life Sciences, Kyungpook National University, Daegu 701-702, Republic of Korea. ${ }^{3}$ Kohat University of Science \& Technology, Kohat, Pakistan.

Received: 5 September 2012 Accepted: 27 May 2013

Published: 31 May 2013

\section{References}

1. Groppa MD, lanuzzo MP, Tomaro ML, Benavides MP: Polyamine metabolism in sunflower plants under long-term cadmium or copper stress. Amino Acids 2007, 32:265-275.

2. Ritter A, Goulitquer S, Salaün JP, Tonon T, Correa JA, Potin P: Copper stress induces biosynthesis of octadecanoid and eicosanoid oxygenated derivatives in the brown algal kelp Laminaria digitata. New Phyto/ 2008, 180:809-821.

3. Weyens N, Lelie D, Taghavi S, Vangronsveld J: Phytoremediation: plantendophyte partnerships take the Challenge. Curr Opin Biotech 2009, 20:248-254

4. Kováčik J, Klejdus B, Hedbavny J, Štork F, Bačkor M: Comparison of cadmium and copper effect on phenolic metabolism, mineral nutrients and stress-related parameters in Matricaria chamomilla plants. Plant Soil 2009, 320:231-242 
5. Contreras L, Moenne A, Gaillard F, Potin P, Correa JA: Proteomic analysis and identification of copper stress-regulated proteins in the marine alga Scytosiphon gracilis (Phaeophyceae). Aquatic Toxicol 2010, 96:85-89.

6. Soleimani M, Hajabbasi MA, Afyuni M, Mirlohi A, Borggaard OK, Holm PE: Effect of endophytic fungi on cadmium tolerance and bioaccumulation by Festuca Arundinacea and Festuca Pratensis. Intern J Phytorem 2010, 12:535-549.

7. Yruela I: Copper in plants. Braz J Plan Physiol 2005, 17:145-156.

8. Ike A, Sriprang R, Ono H, Murooka Y, Yamashita M: Bioremediation of cadmium contaminated soil using symbiosis between leguminous plant and recombinant rhizobia with the MTL4 and the PCS genes. Chemosphere 2007, 66:1670-1676.

9. Rajkumar M, Ae N, Freitas H: Endophytic bacteria and their potential to enhance heavy metal phytoextraction. Chemosphere 2009, 77:153-160.

10. Deng Z, Cao L, Huang H, Jiang X, Wang W, Shi Y, Zhang R: Characterization of $\mathrm{Cd}$ - and Pb-resistant fungal endophyte Mucor sp. CBRF59 isolated from rapes (Brassica chinensis) in a metal-contaminated soil. $J$ Hazard Mat 2011, 185:717-724

11. Schulz B, Boyle C: The endophytic continuum. Mycol Res 2005, 109:661-686.

12. Backman PA, Sikora RA: Endophytes: an emerging tool for biological control. Biol Control 2008, 46:1-3.

13. Redman RS, Kim YO, Woodward CJDA, Greer C, Espino L, Doty SL, Rodriguez RJ: Increased fitness of rice plants to abiotic stress via habitat adapted symbiosis: a strategy for mitigating impacts of climate change. PLoS One 2011, 6:e14823. doi:10.1371/journal.pone.0014823.

14. Khan AL, Hamayun M, Ahmad N, Waqas M, Kang SM, Kim YH, Lee IJ: Exophiala sp. LHL08 reprograms Cucumis sativus to higher growth under abiotic stresses. Physiol Plantarum 2011, 143:329-343.

15. Khan AL, Hamayun M, Kim YH, Kang SM, Lee IJ: Ameliorative symbiosis of endophyte (penicillium funiculosum LHL06) under salt stress elevated plant growth of Glycine max L. Plant Physiol Biochem 2011, 49:852-862.

16. Khan AL, Hamayun M, Khan SA, Kang SM, Shinwari ZK, Kamran M, Rehman S, Kim JG, Lee IJ: Pure culture of Metarhizium anisopliae LHL07 reprograms soybean to higher growth and mitigates salt stress. World J Microb Biotech 2011, 28(4):1483-1494.

17. Khan AL, Hamayun M, Kang SM, Hussain J, Lee IJ: The newly isolated endophytic fungus paraconiothyrium sp. LK1 Produces ascotoxin. Molecules 2012, 17:1103-1112.

18. Alhamed MFA, Shebany YM: Endophytic Chaetomium globosum enhances maize seedling copper stress tolerance. Plant Biol 2012. doi:10.1111/j.1438-8677.2012.00608.x

19. Malinowski DP, Belesky DP: Neotyphodium coenophialum-endophyte infection affects the ability of tall fescue to use sparingly available phosphorus. J Plant Nutrit 1999, 22:835-853.

20. Malinowski DP, Zuo H, Belesky DP, Alloush GA: Evidence for copper binding by extracellular root exudates of tall fescue but not perennial ryegradd infected with Neotyphodium spp. Endophytes. Plant Soil 2004, 267:1-12.

21. Ren G, Chen Y, Zou XK, Zhou YQ: Change in climatic extremes over mainland China based on an integrated extreme climate index. Clim Res 2011, 50:113-124.

22. Xiao X, Luo S, Zeng G, Wei W, Wan Y, Chen L, Guo H, Cao Z, Yang L, Chen J, Xi Q: Biosorption of cadmium by endophytic fungus (EF) Microsphaeropsis sp. LSE10 isolated from cadmium hyperaccumulator Solanum nigrum L. Biores Technol 2010, 101:1668-1674.

23. Li HY, Wei DQ, Shen M, Zhou ZP: Endophytes and their role in phytoremediation. Fungal Div 2012, 54:11-18.

24. Pathan MS, Lee JD, Shannon JG, Nguyen HT: Recent advances in breeding for drought and salt stress tolerance in Soybean. In Advances in molecular breeding toward drought and salt tolerant crops. Edited by Jenks MA, Hasegawa PM, Jain SM. Netherlands: Springer; 2007:739-773.

25. Pan $\mathrm{R}$, Cao L, Zhang R: Combined effects of $\mathrm{Cu}, \mathrm{Cd}, \mathrm{Pb}$, and $\mathrm{Zn}$ on the growth and uptake of consortium of Cu-resistant Penicillium sp. A1 and Cd-resistant Fusarium sp. A19. J Hazard Mat 2009, 171:761-766.

26. White PJ, Broadley MR: Calcium in plants. Ann Bot 2003, 92:487-511.

27. Esterbauer $\mathrm{H}$, Cheeseman $\mathrm{KH}$ : Determination of aldehydic lipid peroxidation products: malonaldehyde and 4-hydroxynonenal. Meth Enzymol 1990, 186:407-421.

28. Pratelli R, Pilot G: Altered amino acid metabolism in Glutamine Dumper plants. Plant Signal Beh 2007, 2:182-184.
29. Iskandar NL, Zainudin NAIM, Tan SG: Tolerance and biosorption of copper (Cu) and lead $(\mathrm{Pb})$ by filamentous fungi isolated from a freshwater ecosystem. J Environ Sci 2011, 23:824-830

30. Zhang D, Duine JA, Kawai F: The extremely high Al resistance of Penicillium janthinellum F-13 is not caused by internal or external sequestration of Al. Biometals 2002, 15:167-174.

31. Massaccesi G, Romero MC, Cazau MC, Bucsinszky AM: Cadmium removal capacities of filamentous soil fungi isolated from industrially polluted sediments, in La Plata (Argentina). World J Microbiol Biotechnol 2002, 18:817-820

32. Barrett G, Campbell CD, Fitter AH, Hodge A: The arbuscular mycorrhizal fungus Glomus hoi can capture and transfer nitrogen from organic patches to its associated host plant at low temperature. App/ Soil Ecol 2011, 48:102-105.

33. Mohanpuria P, Rana NK, Yadav SK: Cadmium induced oxidative stress influence on glutathione metabolic genes of Camellia sinensis (L.) $\mathrm{O}$. Kuntze. Environ Toxicol 2007, 22:368-374.

34. Yadav SK: Heavy metals toxicity in plants: An overview on the role of glutathione and phytochelatins in heavy metal stress tolerance of plants. South Afri J Bot 2010, 76:167-179.

35. Monnet F, Vailant N, Vernay P, Coudret A, Sallanon H, Hitmi A: Relationship between PSIl activity, $\mathrm{CO}_{2}$ fixation and $\mathrm{Zn}, \mathrm{Mn}$ and $\mathrm{Mg}$ contents of Lolium perenne under zinc stress. J Plant Physiol 2001, 158:1137-1144.

36. Rüegsegger A, Schmutz D, Brunold C: Regulation of glutathione synthesis by cadmium in Pisum sativum L. Plant Physiol 1990, 93:1579-1584.

37. Nagalakshmi N, Prasad MNV: Responses of glutathione cycle enzymes and glutathione metabolism to copper stress in Scenedesmus bijugatus. Plant Science 2001, 160:291-299.

38. Lindberg S, Kader MA, Yemelyanov V, Ahmad P: Calcium signalling in plant cells under environmental stress, Prasad MNV, environmental adaptations and stress tolerance of plants in the Era of climate change. New York: Springer; 2012:325-360.

39. Schachtman DP, Reid RJ, Ayling SM: Phosphorus uptake by plants: from soil to cell. Plant Physiol 1998, 116:447-453.

40. Veneklaas EJ, Lambers H, Bragg J, Finnegan PM, Lovelock CE, Plaxton WC, Price CA, Scheible WR, Shane MW, White PJ, Raven JA: Opportunities for improving phosphorus-use efficiency in crop plants. New Phytol 2012, 195:306-320.

41. Ufaz S, Galili G: Improving the content of essential amino acids in crop plants: goals and opportunities. Plant Physiol 2008, 147:316-330.

42. Less H, Galili G: Principal transcriptional programs regulating plant amino acid metabolism in response to abiotic stresses. Plant Physiol 2008, 147:316-330.

43. Tuteja N: Abscisic acid and abiotic stress signaling. Plant Signal Beh 2007, 2:135-138

44. Herrera-Medina MJ, Steinkellner S, Vierheilig H, Ocampo JA, Garrido JM: Abscisic acid determinates arbuscule development and functionality in the tomato arbuscular mycorrhiza. New Phytol 2007, 175:554-564.

45. Mauch-Mani B, Mauch F: The role of abscisic acid in plant-pathogen interactions. Cur Opi Plant Bio 2005, 8:409-414

46. Jahromi F, Aroca R, Porcel R, Ruiz-Lozano JM: Influence of salinity on the in vitro development of Glomus intraradices and on the in vivo physiological and molecular responses of mycorrhizal lettuce plants. Microb Eco 2008, 55:45-53.

47. Sharp RE, LeNoble ME, Else MA, Thorne ET, Gherardi F: Endogenous ABA maintains shoot growth in tomato independently of effects on plant water balance: evidence for an interaction with ethylene. J Exp Bot 2000, 51:1575-1584

48. Russell AD, Hugo WB, Ayliffe GAJ: Principles and practice of disinfection Boston, MA, USA: Preservation and Sterilization. Blackwell Scientific Publications; 1982:653.

49. Waller F, Achatz B, Baltruschat H, Fodor J, Becker K, Fischer M, Heier T, Huckelhoven R, Neumann C, Wettstein D, Franken P, Kogel KH: The endophytic fungus Piriformis indica reprograms barley to salt-stress tolerance, disease resistance, and higher yield. PNAS 2005, 102:13386-13391.

50. Lichtenthaler HK: Chlorophylls and carotenoids: pigment of photosynthetic biomembranes. Method Enzymol 1987, 148:350-382.

51. González L, González-Vilar M: Determination of relative water content and electrolytic leakage. In Handbook of plant ecophysiology techniques. Edited by Roger MJR. Dordrecht Netherlands: Springer; 2003:207-212. 
52. Ohkawa H, Ohishi N, Yagi K: Assay of lipid peroxides in animal tissue by thiobarbituric acid reaction. Anal Biochem 1979, 95:351-358.

53. Ellman G: Tissue sulphydryl groups. Archi Biochem Biophy 1959, 32:70-77.

54. Lu L, Tian SK, Yang X, Li TQ, He ZL: Cadmium uptake and xylem loading are active processes in the hyperaccumulator Sedum alfredii. J Plant Physiol 2009, 166:579-587.

55. Kamboj JS, Blake PS, Quinlan JD, Baker DA: Identification and quantification by GC-MS of zeatin and zeatin riboside in xylem sap from rootstock and scion of grafted apple trees. Plant Growth Regu 1999, 28:199-205

doi:10.1186/1471-2229-13-86

Cite this article as: Khan and Lee: Endophytic Penicillium funiculosum LHL06 secretes gibberellin that reprograms Glycine max L. growth during copper stress. BMC Plant Biology 2013 13:86.

\section{Submit your next manuscript to BioMed Central and take full advantage of:}

- Convenient online submission

- Thorough peer review

- No space constraints or color figure charges

- Immediate publication on acceptance

- Inclusion in PubMed, CAS, Scopus and Google Scholar

- Research which is freely available for redistribution 